\title{
Is Mistletoe Treatment Beneficial in Invasive Breast Cancer? A New Approach to an Unresolved Problem
}

\author{
PETER FRITZ ${ }^{1}$, JÜRGEN DIPPON ${ }^{2}$, SIMON MÜLLER ${ }^{2}$, SVEN GOLETZ $^{2}$, CHRISTIAN TRAUTMANN $^{3}$, \\ XENOPHON PAPPAS ${ }^{4}$, GERMAN OTT ${ }^{1}$, HILTRUD BRAUCH ${ }^{5}$, MATTHIAS SCHWAB $^{5,6}$, \\ STEFAN WINTER ${ }^{5}$, THOMAS MÜRDTER ${ }^{5}$, FRIEDHELM BRINKMANN ${ }^{7}$, SIMONE FAISST $^{7}$, \\ SUSANNE RÖSSLE ${ }^{7}$, ANDREAS GERTEIS $^{3}$ and GODEHARD FRIEDEL ${ }^{8}$ \\ ${ }^{1}$ Department of Clinical Pathology, Robert Bosch Hospital, Stuttgart, Germany; \\ ${ }^{2}$ Institute of Stochastics and Applications, University of Stuttgart, Stuttgart, Germany; \\ ${ }^{3}$ Department of Gynecology and Obstetrics, Robert-Bosch-Hospital, Stuttgart, Germany; \\ ${ }^{4}$ Radiologie Nuklearmedizin Winnenden, Winnenden, Germany; \\ ${ }^{5}$ Margarete Fischer-Bosch-Institute of Clinical Pharmacology and University of Tuebingen, Stuttgart, Germany; \\ ${ }^{6}$ Department of Clinical Pharmacology, University Hospital Tuebingen, Stuttgart, Germany; \\ ${ }^{7}$ Onkologischer Schwerpunkt Stuttgart e.V., Stuttgart, Germany; \\ ${ }^{8}$ Center for Pulmonology and Thoracic Surgery, Klinik Schillerhöhe, Stuttgart-Gerlingen, Germany
}

\begin{abstract}
Background/Aim: In this retrospective study, we compared breast cancer patients treated with and without mistletoe lectin I (ML-I) in addition to standard breast cancer treatment in order to determine a possible effect of this complementary treatment. Patients and Methods: This study included 18,528 patients with invasive breast cancer. Data on additional ML-I treatments were reported for 164 patients. We developed a "similar case" method with a distance measure retrieved from the beta variable in Cox regression to compare these patients, after stage adjustment, with their non-ML-1 treated counterparts in order to answer three hypotheses concerning overall survival, recurrence free survival and life quality. Results: Raw data analysis of an additional ML-I treatment yielded a worse outcome $(p=0.02)$ for patients with ML treatment, possibly due to a bias inherent in the ML-I- treated patients. Using the "similar case" method (a case- based reasoning approach) we could not confirm this harm for patients using ML-I. Analysis of life quality data did not demonstrate reliable differences between patients treated with ML-I treatment and those without proven ML-I treatment. Conclusion: Based on a "similar case" model we did not observe any differences in the overall
\end{abstract}

Correspondence to: Godehard Friedel, Klinik Schillerhöhe, Center for Pulmonology and Thoracic Surgery, Solitudestr. 18, 70839 Stuttgart, Germany. Tel: +49 71562037241, Fax: +49 71562037003, e-mail: godehard.friedel@klinik-schillerhoehe.de

Key Words: ML 1, breast cancer treatment, complementary medicine, prognosis. survival (OS), recurrence- free survival (RFS), and quality of life data between breast cancer patients with standard treatment and those who in addition to standard treatment received ML-I treatment.

Treatment of breast cancer is based on an elaborate decision tree, which is influenced by the patho-morphological features of breast cancer, the knowledge of the physician in charge, and the decision of the patient. Even for the well justified treatment modalities, the benefits of a certain decision are hard to measure, as revealed by Adjuvant Online (1). In addition to standard treatment, complementary therapies are also used in breast cancer, mostly at the request of the patient (2). Mistletoe lectin (ML-I) is one of the most frequently complementary treatment options (3). There are some studies (4-16) that argue ML-I treatment may be beneficial if given in addition to standard treatment. The benefits claimed for this ML-I treatment are: 1$)$ improvement in the patient's quality of life $(5,7,8,10$, $11,13), 2)$ reduction of cancer-related fatigue or side effects of anti-cancer chemotherapy $(6,9,14), 3)$ improvement of relapse free survival (RFS), and 4) improvement of overall survival (OS) $(17,18)$. However, seen by the perspective of patients, the problem of decision making for or against a complementary ML-I treatment in a given breast cancer are not solved. Based on a plethora of data (retrospective, prospective and scientific) the patient or the patient and the physician in charge had to do a binary (no/yes) decision.

Here, we use a new statistical approach (case-based reasoning) to analyze retrospective data $(19,20)$. Three hypotheses were tested: Additional ML-I treatment had no statistically significant harm or benefit on OS and RFS 
(hypotheses 1 and 2). Life quality data are not different in patients treated with ML-I in addition to a conventional treatment approach.

\section{Patients and Methods}

Patients. All data were retrieved from the breast cancer data base of the OSP Stuttgart (Onkologischer Schwerpunkt Stuttgart) (19, 20). Patients were diagnosed with breast cancer from January 1 , 1989- March 31, 2011. Patients $(\mathrm{N}=18,528)$ with invasive breast cancer were available for analysis. $\mathrm{pT}, \mathrm{pN}, \mathrm{M}$ were classified following TNM classification (Table I) (21). PN1mi was classified as $\mathrm{pN} 1$. The biological disease modifiers, ER (estrogen receptor), $\mathrm{PR}$ (progesterone receptor), and cerb-B2 were reported as immunoreactive scores (Remmele score, levels: 0-4, 6, 8, 9, and 12) (22) and cerb-b2 with levels 0-3. A breast cancer was considered ER or PR positive if the Remmele score was $>1$ (22). Cerb-B2 was considered positive for an immunohistochemical score of 3 . The distribution of $\mathrm{T}, \mathrm{N}$, and $\mathrm{M}$ (as shown in Table I) was used to calculate the stage and substage following the TNM recommendation (21). Two subsets were compared in the raw data analysis: 1) ML-I Subset. These are patients with a proven ML-I treatment $(\mathrm{N}=164)$, and 2) NON-ML-I subset. These are all patients with breast cancer in the OSP registry without reported ML-I treatment $(\mathrm{N}=18,528-164=18364)$.

Similar patients were selected by a statistical approach (see below) and two collectives were analyzed following the recommendations of Austin (23). Model 1: Similarity was defined by 8 variables (Table I): pT, pN, M, age (cut-off 60 years), year of diagnosis (cut-off year=2000), chemotherapeutical treatment, antihormonal treatment, and radiation.

Model 2: Similarity was defined by those 4 variables which were significantly different between the 164 ML-I treated breast cancers and their counterparts without proven ML-I treatment. The variables selected for assessment of similarity were $\mathrm{pT}, \mathrm{pN}$, age, year of diagnosis.

Treatment data. The reports available contained information about: 1) chemotherapy (yes/no, not available), with yes indicating patients were treated with one or more chemotherapies without further specification; 2) radiation (yes/no, not available), with yes indicating patients treated with one or more radiation treatments without further specification; and 3) anti-hormonal treatment (yes/no, not available), with yes indicating patients received one or more anti-hormonal treatments without further specification. In addition, 164 patients received mistletoe treatment (ML-I). Different pharmacological variants were applied: LectinolR, Abnoba $^{R}$, Helixor ${ }^{R}$, Iscador ${ }^{R}$, and Aviscumine ${ }^{R}(24,25)$. Our retrospective data did not allow to discriminate between these 5 treatment modalities. All other patients had either no ML-I application or this treatment was not disclosed in the medical reports (25). In a subset of patients receiving chemotherapy information about a specific treatment consisting of cyclophosphamide, methotrexate, and fluorouracil (CMF) was available. For patients receiving anti-hormonal treatment, records indicated whether this treatment was tamoxifen or an aromatase inhibitor (not further subdivided) (25).

Survival. OS was calculated from the date of diagnosis to either death or last registration. Death could only rarely be classified as either tumor-related or not tumor-related. Therefore, all causes of death were taken into consideration. For comparing non-tumor related deaths, we utilized the life table of the Federal Statistical Office of Germany (26). The RFS was defined as the time between diagnosis and either death from any cause, local relapse, or distant metastasis.

Subset analysis. Five subsets were analyzed. 1) high risk patients defined by G3 breast cancer, 2) low risk patients defined as pT1 or pT2, N0, G1 or G2, 3) patients aged $>50$ years, 4) patients with a CMF chemotherapy, and 5) tamoxifen treatment.

Life quality analysis. In 3633 patients a life quality assessment was performed using the EORTC QLQ-C30 version 3.0. This assessment consisted of 30 questions with an item range of mostly 3 or 6 (question 29 and 30 concerning global health status) $(27,28)$. For 101 patients of our case based reasoning procedure (CBR) model these life data were available. From each patient, at least, two questionnaires were available. The hypothesis tested was two sided and the level of significance was set at $p=0.05$. The hypothesis was that ML-I treatment has a significant influence on life quality. For eviting a false interpretation by a multiple testing approach, we performed a Bonferroni-Holm correction with $n=15$ (number of different tests in the scoring system of QLQ-C30). The EORTC QLQ-C30 discriminates between symptom scales (0-100) higher values signifying more intensive symptoms (decreased life quality) and functionating scales higher values signifying good life quality. We analyzed 1) the first life quality assessment, 2) the mean of life quality assessment, if more than one assessment was done, and 3) the change in the life quality scales, if more than one assessment was done, discriminating three groups: no change, increase or decrease of life quality variables. Analysis was done with model 1 or model 2 data sets separately.

Statistical analyses. The data used for analysis correspond to a retrospective study in which the total population of patients suffering from breast cancer in the area of Stuttgart is analyzed (25). The overall survival data were retrieved from the life table of the Statistische Bundesamt Deutschland (26). Data analysis was performed with R, version 3.3.2 (29) and a function written by the authors to select cases from a registry that are similar to a given case $(19,20,30)$. To be more specific, as a first step this function computes the beta vector of the log hazard ratios in a Cox regression set up with the factors to be considered in the given case. In a second step, this beta vector is used to define a distance on the space of the possible values of the chosen factors. Finally, in a third step, $\mathrm{N}=3$ cases out of the data set, nearest to the given case in the sense of the computed distance, are determined. The selection of the matched cases was done with replacement. By this method, for each case of a small subset from a data set, $\mathrm{N}$ cases from the entire data set can be matched. Then, by log-rank test, survival of the subset and the matched data set can be compared. Taken into consideration "the lack of consensus in the literature as to which variables one should include in the propensity score" we followed the recommendation (model 1) of Austin (23) to use variables with presumed prognostic effect. His second recommendation for as few variables as possible was followed in model 2. The matching procedure takes into account both the importance of the considered factors with respect to survival and the natural ordering of factor levels. The variables selected for 
Table I. Clinical and pathological findings of study patients (raw data analysis).

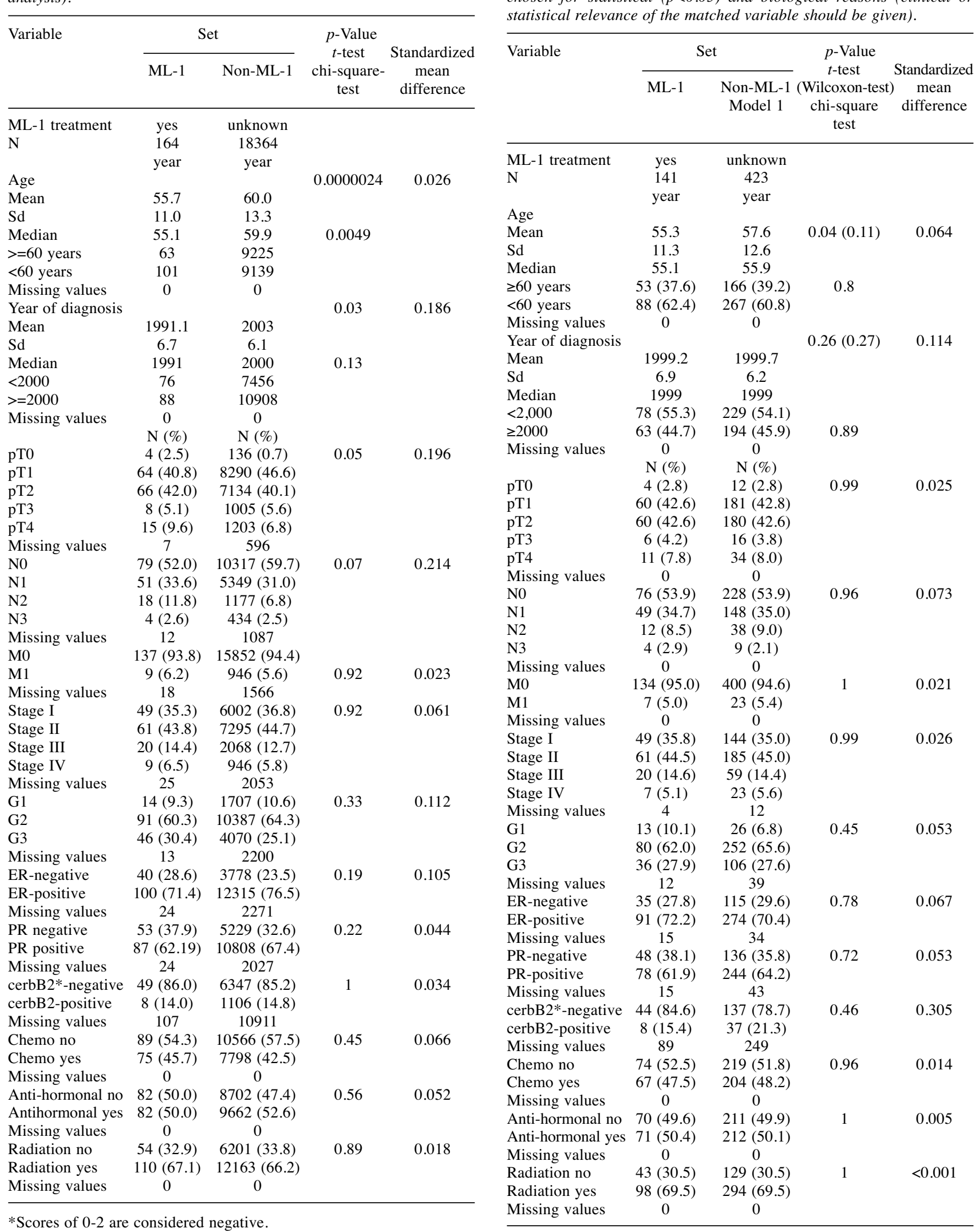

Table II. Comparison of case based reasoning data. Similar cases were chosen for statistical $(p<0.05)$ and biological reasons (clinical or statistical relevance of the matched variable should be given). 
choosing similar cases are: pT, pN, M, age (cut-off 60 years), year of diagnosis (cut-off year=2000), chemotherapeutic treatment, antihormonal treatment, and radiation (model 1). In model $2 \mathrm{pN}, \mathrm{pT}$, age and year of diagnosis entered the model.

To judge the power of our study, we recall that the relation of subset size of proven and non-proven ML-I treatment cases was 1:3, and the 10-year survival rate in the non-proven ML subset was 0.55 . If we request a power of 0.8 , the number of events needed is $267 / 499 / 1172$ to prove that 10 -year survival in the proven ML-I subset is increased by $20 \% / 15 \% / 10 \%$ (event size calculation according to Collett (31). However, due to censoring we must include even more cases. Supposing that recruiting and follow-up time each equals 10 years, the total sample sizes mount up to 491/898/2071, respectively.

We used the $t$-test, the Wilcoxon-test and the statistical mean difference for comparison of numerical data, and the chi-square test or fisher test for categorical data. Statistical hypothesis test is not considered as a valid tool to check the balance of matched data. Nevertheless, for sake of convenience we included $p$-values in an additional column. The effect size (mean statistical difference) was considered to be small $(<0.2)$, medium $(0.2-0.49)$ or large $(\geq 0.5)$ (32). Differences in survival were analyzed with the log-rank test and the Cox survival test. $p$-Values less than 0.05 were considered statistically significant and $p<0.001$ as highly significant. $p$-Values less than $10^{-6}$ were termed $p=0$.

\section{Results}

Patients: We first analyzed the population of all breast cancer patients of a south-western region in Germany and divided it into two subsets (1) breast cancer patients treated with ML-I and (2) those without a reported ML-I treatment (not-ML-I treated) (Table I). Most patients were classified as stage I or II invasive breast cancer, ER or PR positive, and cerb-B2 negative. However, the ML-I treated subset showed significantly more patients with higher $\mathrm{pT}$ and $\mathrm{pN}$. The mean age of the ML-I treated patients was 55.7 years (median 55.1, sd $=11.0$, inter quantile range $(I Q R)=15.41$, range $=29.2-81.0$ years) versus 60.0 years $($ median=59.9, sd=13.3, IQR=19.07, range=18.2-101.4 years) for the Non-ML-I treated patient group. The ML-I treated patients were approximately 4 years younger than the whole population $(p=0)$. Therefore, both subsets, the large without reported ML-I treatment $(\mathrm{N}=18,364)$ and the small one with reported ML-I treatment $(\mathrm{N}=164)$ are highly biased. A direct comparison between both subsets in Table I is hampered by many biases as shown by the standardized mean difference or statistically significant different distributions of age, $\mathrm{pT}$, year of diagnosis and $\mathrm{pN}$. Concerning the treatment data (raw data, Table I) ML-I treated patients and those without a reported ML-I treatment had no statistical difference. After selecting the similar case patients either with model 1 or 2 we found no differences between the subsets of ML-I treated patients and their most similar counterparts (Tables II and III) based on the statistical mean difference.
Table III. Comparison of case based reasoning data. Similar cases were chosen for statistical $(p<0.05)$ reasons only.

\begin{tabular}{|c|c|c|c|c|}
\hline \multirow[t]{2}{*}{ Variable } & \multicolumn{2}{|c|}{ Set } & \multirow{2}{*}{$\begin{array}{c}p \text {-Value } \\
\text { t-test } \\
\text { (Wilcoxon-test) } \\
\text { chi-square } \\
\text { test }\end{array}$} & \multirow{2}{*}{$\begin{array}{l}\text { Standardized } \\
\text { mean } \\
\text { difference }\end{array}$} \\
\hline & ML & $\begin{array}{l}\text { Non-ML } \\
\text { Model } 2\end{array}$ & & \\
\hline ML-1 treatment & yes & unknown & & \\
\hline $\mathrm{N}$ & $\begin{array}{l}151 \\
\text { year }\end{array}$ & $\begin{array}{l}453 \\
\text { year }\end{array}$ & & \\
\hline Age & & & $0.82(0.89)$ & 0.042 \\
\hline Mean & 55.5 & 55.7 & & \\
\hline $\mathrm{Sd}$ & 11.2 & 11.8 & & \\
\hline Median & 55.1 & 55.2 & & \\
\hline$>=60$ years & $58(38.4)$ & $174(38.4)$ & 0.68 & \\
\hline$<60$ years & 93 (61.6) & 279 (61.6) & & \\
\hline Missing Values & 0 & 0 & & \\
\hline Year of diagnosis & & & $0.51(0.52)$ & 0.026 \\
\hline Mean & 1999.2 & 1999.6 & & \\
\hline $\mathrm{Sd}$ & 6.8 & 6.8 & & \\
\hline Median & 1999 & 1999 & & \\
\hline$<2000$ & $86(57.0)$ & $247(54.5)$ & & \\
\hline$>=2000$ & $65(43.0)$ & $206(45.5)$ & 0.68 & \\
\hline Missing values & $\begin{array}{c}0 \\
\mathrm{~N}(\%)\end{array}$ & $\begin{array}{c}0 \\
\mathrm{~N}(\%)\end{array}$ & & \\
\hline pT0 & $4(2.6)$ & $9(2.0)$ & 0.97 & 0.033 \\
\hline pT1 & $64(42.4)$ & $193(42.6)$ & & \\
\hline pT2 & $62(41.1)$ & $185(40.8)$ & & \\
\hline pT3 & $8(5.3)$ & $21(4.6)$ & & \\
\hline pT4 & $13(8.6)$ & 45 (9.9) & & \\
\hline Missing values & 0 & 0 & & \\
\hline N0 & 78 (51.7) & $230(50.8)$ & 0.82 & 0.064 \\
\hline N1 & $51(39.8)$ & $160(35.3)$ & & \\
\hline $\mathrm{N} 2$ & $18(11.9)$ & $50(11.0)$ & & \\
\hline N3 & $4(2.6)$ & $13(2.9)$ & & \\
\hline Missing values & 0 & 0 & & \\
\hline M0 & $134(95.0)$ & $392(93.8)$ & 0.73 & 0.086 \\
\hline M1 & $7(5.0)$ & $26(6.2)$ & & \\
\hline Missing values & 10 & 35 & & \\
\hline Stage I & $49(35.8)$ & $141(34.4)$ & 0.93 & 0.102 \\
\hline Stage II & $61(44.5)$ & $177(43.3)$ & & \\
\hline Stage III & $20(14.6)$ & $65(15.9)$ & & \\
\hline Stage IV & $7(5.1)$ & $26(6.4)$ & & \\
\hline Missing values & 14 & 44 & & \\
\hline G1 & $13(9.4)$ & $31(7.9)$ & 0.77 & 0.125 \\
\hline G2 & 87 (62.6) & $258(65.6)$ & & \\
\hline G3 & $39(38.0)$ & $104(26.5)$ & & \\
\hline Missing values & 12 & 60 & & \\
\hline ER-negative & $38(28.4)$ & $83(21.0)$ & 0.1 & 0.014 \\
\hline ER-positive & 96 (71.6) & $313(79.0)$ & & \\
\hline Missing values & 17 & 60 & & \\
\hline PR-negative & $51(38.1)$ & $126(32.0)$ & 0.24 & 0.017 \\
\hline PR-positive & 83 (61.6) & $268(68.0)$ & & \\
\hline $\begin{array}{l}\text { Missing values } \\
\text { cerbB2*-negative }\end{array}$ & 17 & 59 & & \\
\hline Negative & $46(85.2)$ & $141(82.0)$ & 0.74 & 0.172 \\
\hline Positive & $8(14.8)$ & $31(31.0)$ & & \\
\hline Missing values & 97 & 281 & & \\
\hline Chemo no & $81(53.6)$ & $237(52.3)$ & 0.85 & 0.013 \\
\hline Chemo yes & $70(56.4)$ & $216(47.7)$ & & \\
\hline Missing values & 0 & 0 & & \\
\hline Anti-hormonal no & $74(49.0)$ & $215(47.5)$ & 0.81 & 0.013 \\
\hline Anti-Hormoal yes & $77(51.0)$ & $238(52.5)$ & & \\
\hline Missing values & 0 & 0 & & \\
\hline Radiation no & $47(31.1)$ & $154(34.0)$ & 0.58 & 0.024 \\
\hline Radiation yes & $104(68.9)$ & $299(66.0)$ & & \\
\hline Missing values & 0 & 0 & & \\
\hline
\end{tabular}


Table IV. Effects of ML-1 treatment on survival of breast cancer patients.

\begin{tabular}{lcccc}
\hline $\begin{array}{l}\text { ML treatment } \\
\text { in COX } \\
\text { survival model }\end{array}$ & $\begin{array}{l}\text { Kind of } \\
\text { analysis }\end{array}$ & $p$-Value & $\begin{array}{c}\text { 95\%CI- } \\
\text { intervall }\end{array}$ & $\begin{array}{c}\text { Commentary } \\
\text { (with respect to } \\
\text { overall survival) }\end{array}$ \\
\hline $\begin{array}{l}\text { ML-1 all stages } \\
\text { ML-1 and stage }\end{array}$ & Raw data & 0.021 & $1.0-1.2$ & ML-1 is detrimental \\
Stage I & & 0.88 & 0.34 & No effect of ML-1 \\
Stage II & & 0.05 & $1.0-2.2$ & ML-1 is detrimental \\
Stage III & & 0.04 & $1.0-3.2$ & ML-1 is detrimental \\
Stage IV & & 0.78 & $0.4-2.1$ & No effect of ML-1 \\
ML-1 all stages & Model-1 & 0.99 & $0.72-1.4$ & No effect of ML-1 \\
ML-1 and stage & Model-1 & & & \\
Stage I & & 0.29 & $0.23-1.55$ & No effect of ML-1 \\
Stage II & & 0.19 & $0.86-2.14$ & No effect of ML-1 \\
Stage III & & 0.39 & $0.7-2.6$ & No effect of ML-1 \\
Stage IV & & 0.64 & $0.25-2.3$ & No effect of ML-1 \\
ML-1 all stages & Model-2 & 0.50 & $0.66-1.22$ & No effect of ML-1 \\
ML-1 and stage & Model-2 & & & \\
Stage I & & 0.56 & $0.28-2.0$ & No effect of ML-1 \\
Stage II & & 0.88 & $0.62-1.5$ & No effect of ML-1 \\
Stage III & & 0.54 & $0.64-2.32$ & No effect of ML-1 \\
Stage IV & & 0.62 & $0.27-2.20$ & No effect of ML-1 \\
\hline
\end{tabular}

Survival analysis. When we analyzed the survival difference between patients treated (ML-I group) and not treated with ML-I (Non-ML-I group) in the raw data population, we found a harmful effect for the ML-I treated patients $(95 \% \mathrm{CI}-$ interval $=1-1.2, p=0.02$ ) (Table IV, Figure 1) with regard to survival. When we analyzed the data in a stage-adjusted manner, the harmful effects of the ML-I treatment were determined in stage II (95\% CI-interval $=1-2.2, p=0.05)$ and III (95\%CI-interval=1-3.2, $p=0.04$ ) (Table IV).

When we repeated the survival analysis using a similar case approach, this disadvantage disappeared (Figure 2 and Table IV) independent of the choice of variables (model 1 and 2). Adding stage to the Cox analysis (Table IV) confirmed this result. In model 1 population, similarity was defined on the basis of T, N, M, age (cut-off= 60 years), year of diagnosis (cut-off=year of diagnosis 2000), chemotherapy, anti-hormonal treatment and radiation. The 5-year survival, for example, was $75.1 \%(95 \% \mathrm{CI}=67.6-83.3)$ in the ML-I treated subset (Table II and Figure 1) and $78.4 \%$ $(95 \% \mathrm{CI}=74.4-82.6)$ in the similar subset. For comparison, a woman aged 60 years without breast cancer has a 5 -year survival of $96.9 \%$ ("Überlebensdaten Statistisches Bundesamt" 2009/201) (26). There were no significant differences in the RFS $(p=0.4)$, when comparing ML-I treated with "not-treated" patients. When we repeated the analysis with the similar case group chosen by model 2 the results did not change (Table IV).

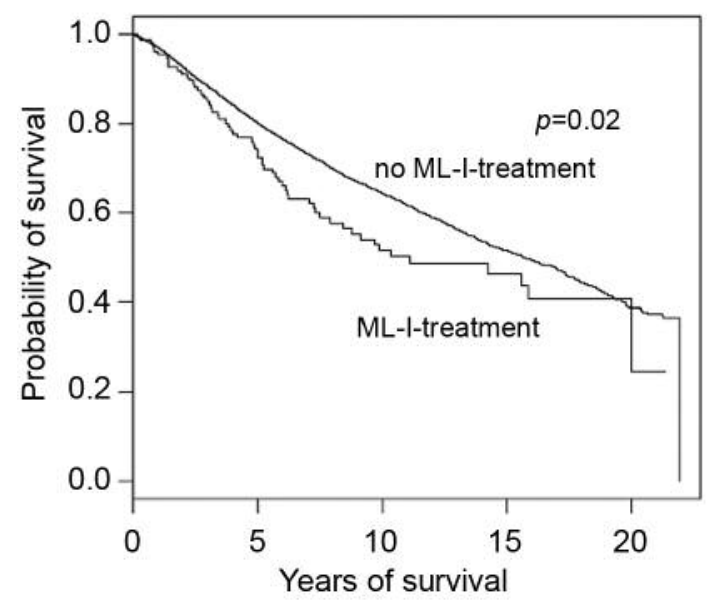

Figure 1. Comparison of patients with ML-I treatment to those without reported ML-I treatment (raw data).

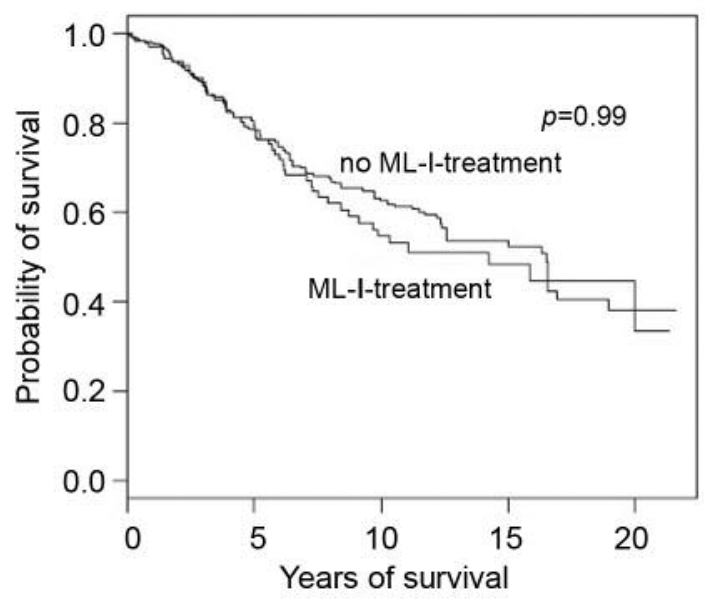

Figure 2. Comparison of patients with ML-I treatment to those without reported ML-1 treatment (analysis with matched data).

Life quality analysis. A total of 101 out of 604 patients $(13.1 \%)$ provided data for evaluation of life quality (Table V) $(27,28)$. Physical functioning, role functioning, emotional functioning, cognitive functioning and social functioning were not affected by an additional ML-I treatment (Tables V and VI). This holds true for analysis of the first life quality assessment or the mean of life quality assessments. If we analyzed the proportion of patients with increasing life quality in the global health scale, we observed non-improved health life quality $(p=0.82)$. All other variables (symptoms or scales) did not show statistically significant differences between the ML-1 and Non-ML-1 treated patient groups (Table VI). 
Table V. Life quality functionating scales in ML-1-treated and non-ML-1-treated patients.

\begin{tabular}{|c|c|c|c|c|}
\hline Variable & Abbr & ML-1 & Non-ML-1 & $p$-Value \\
\hline Physical functionating & PF2 & & & \\
\hline First evaluation median & & 76.5 & 80 & 0.4 \\
\hline Interquantile & & 27 & 26 & \\
\hline Median of all evaluations & & 75.3 & 80.7 & 0.14 \\
\hline Interquantile & & 22.7 & 14 & \\
\hline Increase N (\%) & & $6 / 23(26.1)$ & 21/77 (27.3) & 1 \\
\hline Role functionating & RF2 & & & \\
\hline First evaluation median & & 50 & 67 & 0.61 \\
\hline Interquantile & & 45.8 & 37.3 & \\
\hline Median of all evaluations & & 60.3 & 66.7 & 0.23 \\
\hline Interquantile & & 38.8 & 25 & \\
\hline Increase $\mathrm{N}(\%)$ & & $4 / 22(18.2)$ & 12/77 (15.6) & 1 \\
\hline Emotional functionating & $\mathrm{EF}$ & & & \\
\hline First evaluation median & & 58 & 75 & 0.31 \\
\hline Interquantile & & 39.5 & 42 & \\
\hline Median of all evaluations & & 65.9 & 73.3 & 0.40 \\
\hline Interquantile & & 31.1 & 25.9 & \\
\hline Increase N (\%) & & $5 / 21(23.8)$ & $32 / 75(42.7)$ & 0.19 \\
\hline Cognitive functionating & $\mathrm{CF}$ & & & \\
\hline First evaluation median & & 83 & 83 & 0.61 \\
\hline Interquantile & & 33 & 17 & \\
\hline Median of all evaluations & & 83.3 & 88.3 & 0.72 \\
\hline Interquantile & & 36.8 & 28.3 & \\
\hline Increase N (\%) & & $6 / 23(26.1)$ & $33 / 77(42.9)$ & 0.23 \\
\hline Social functionating & SF & & & \\
\hline First evaluation median & & 67 & 83 & 0.16 \\
\hline Interquantile & & 41.5 & 33 & \\
\hline Median of all evaluations & & 66.7 & 75 & 0.33 \\
\hline Interquantile & & 28.5 & 30 & \\
\hline Increase $\mathrm{N}(\%)$ & & $5 / 23(21.7)$ & 28/77 (36.4) & 0.29 \\
\hline Global health status & QI2 & & & \\
\hline First evaluation median & & 50 & 66.7 & 0.23 \\
\hline Interquantile & & 25 & 25 & \\
\hline Median of all evaluations & & 62.5 & 66.7 & 0.5 \\
\hline Interquantile & & 21.6 & 22.5 & \\
\hline Increase $\mathrm{N}(\%)$ & & $8 / 23(34.8)$ & $31 / 77(40.3)$ & 0.82 \\
\hline
\end{tabular}

Interpretation: life quality functionating scales range between $0-100$. A high life function scale signifies a good life quality. No differences in life quality were observed between ML-I treated and Non-ML-I patient groups in the functionating scale.

\footnotetext{
Subset analysis (ML-I treated patients versus Non-ML-I treated patients) in model 1 and 2 . If we analyzed only patients treated with tamoxifen or CMF, we found no statistically significant harm for the additional ML-I treated patients $(p=0.98$, respectively $p=0.31$ ). The same holds true for the $\mathrm{G} 1, \mathrm{G} 2$ and G3 subsets ( $p=0.10, p=0.44$, respectively $p=0.27)$, the low and high-risk group ( $p=0.33$, respectively 0.29 ).
}

Table VI. Symptoms scales of life quality variables in ML-1 treated and non-ML-1 treated patients.

\begin{tabular}{|c|c|c|c|c|}
\hline Variable & Abbr & ML-1 & Non-ML-1 & $p$-Value \\
\hline Fatigue & FA & & & \\
\hline First answer median & & 44 & 44 & 0.59 \\
\hline Interquantile & & 45 & 45 & \\
\hline Median & & 38.9 & -37.8 & 0.32 \\
\hline Interquantile & & 31.1 & 32.3 & \\
\hline $\begin{array}{c}\text { Increase of life } \\
\text { quality } N(\%)\end{array}$ & & $6 / 23(26.1)$ & 20/77 (26.0) & 1 \\
\hline Nausea and vomiting & NV & & & \\
\hline First answer median & & 0 & 0 & 0.32 \\
\hline Interquuantile & & 17 & 0 & \\
\hline Median & & 0 & 0 & 0.76 \\
\hline Interquantile & & 15.5 & 8.3 & \\
\hline Increase & & $1 / 22(4.5)$ & $16 / 77(20.8)$ & 0.14 \\
\hline Pain & PA & & & \\
\hline First answer median & & 33 & 17 & 0.30 \\
\hline Interquantile & & 41.5 & 50 & \\
\hline Median & & 25 & 23.3 & 0.64 \\
\hline Interquantile & & 25.8 & 41.7 & \\
\hline Increase & & $5 / 23(21.7)$ & $19 / 77(24.7)$ & 1 \\
\hline Dyspnea & Dy & & & \\
\hline First answer median & & 33 & 0 & 0.15 \\
\hline Interquantile & & 67 & 33 & \\
\hline Median & & 33.3 & 16.7 & 0.17 \\
\hline Interquantile & & 46.7 & 33.3 & \\
\hline Increase & & $6 / 23(26.1)$ & $20 / 77(26.0)$ & 1 \\
\hline Insomnia & SL & & & \\
\hline First answer median & & 33 & -3 & 0.72 \\
\hline Interquantile & & 67 & 33 & \\
\hline Median & & 33.3 & 33.3 & 0.74 \\
\hline Interquantile & & 55 & 23.3 & \\
\hline Increase & & $42 / 23(8.7)$ & 17/77 (22.1) & 0.26 \\
\hline Appatite loss & AP & & & \\
\hline First answer median & & 0 & 0 & 0.20 \\
\hline Interquantile & & 33 & 33 & \\
\hline Median & & 0 & 0 & 0.26 \\
\hline Interquantile & & 25 & 10 & \\
\hline Increase & & $1 / 22(4.4)$ & $12 / 77(15.6)$ & 0.29 \\
\hline Constipation & $\mathrm{CO}$ & & & \\
\hline First answer median & & 0 & 0 & 0.50 \\
\hline Interquantile & & 0 & 33 & \\
\hline Median & & 0 & 0 & 0.97 \\
\hline Interquantile & & 29.2 & 28.0 & \\
\hline Increase & & $3 / 22(13.6)$ & 13/77 (16.9) & 0.97 \\
\hline Diarrhea & DI & & & \\
\hline First answer median & & 0 & 0 & 0.89 \\
\hline Interquantile & & 0 & 0 & \\
\hline Median & & 0 & 0 & 0.30 \\
\hline Interquantile & & 3.4 & 10 & \\
\hline Increase & & $1 / 23(4.4)$ & 10/77 (13.0) & 0.43 \\
\hline Financial difficulties & FI & & & \\
\hline First answer median & & 0 & 0 & 0.71 \\
\hline Interquantile & & 33 & 33 & \\
\hline Median & & 0 & 33.3 & 0.23 \\
\hline Interquantile & & 6.7 & 26.7 & \\
\hline Increase & & $2 / 23(8.7)$ & $12 / 77(15.6)$ & 0.62 \\
\hline
\end{tabular}

Interpretation: symptoms scales range between 0-100. A high symptom scale signifies more or more intensive symptoms. No differences of life quality were observed between ML-I treated and Non-ML-I patient groups in the symptom scales. 


\section{Discussion}

ML-I is a proven toxin with distinct biological effects on the immune system (33-36) and tumor cells, including triggering off necrosis and apoptosis (37). The A chain inhibits protein synthesis at the ribosomal level and the A and B chains have different immunological effects (38-40). In addition, ML-I has been shown to bind to breast cancer cells in paraffin sections (41).

According to Fasching and coworkers (10), 48.7\% of patients with breast cancer receive a complementary treatment, including ML-I. Therefore, we selected three similar cases for each ML case, assuming that $75 \%$ of nonML1 patients did not receive complementary treatment.

As many oncologists $(42,43)$ argue against the use of cancer patient data in retrospective studies investigating treatment modalities as there are many unknown data biases and a high number of missing values we analyzed our data in two ways (1) raw data analysis and (2) data analysis with a case based reasoning procedure.

In the first approach, we compared the whole set of patients treated with ML-I (in addition to conventional treatment) (see Table I and Figure 1) with those without a reported ML-I treatment. We found a significant disadvantage for the addition of ML-I treatment. However, this approach has to be strongly criticized due to many missing values, unknown bias, and changing treatment modalities over time, factors which may corrupt the results of the data analysis. This comparison is therefore worthless for clinical decision making. For example, the ML-I patients were four years younger than their counterparts without a documented ML1 treatment.

Based on these shortcomings of the first approach, we developed a second method (matching), where three similar cases with the same or very similar features in regards to $\mathrm{T}$, $\mathrm{N}, \mathrm{M}$, age, chemotherapeutical- anti-hormonal treatment, radiation, year of diagnosis were identified for each case of breast cancer treated with ML-I. With this new approach, we did not find any benefit or harm of ML-I treatment with concern to OS (Figure 2 and Table IV), RFS or for any of the subsets studied. The strategy for selecting variables for the CBR was based on at least one of two criteria: (1) a statistical significant difference in the variables mentioned in Table I, and (2) a probable clinical impact of a variable on the course of the disease. The results of the survival analysis did not differ (Table IV) irrespective whether model 1 or model 2 data were used for the Cox regression analysis.

Concerning life quality data an additional ML-I treatment had also no influence on the assessment of life quality questionnaire, independent from whether symptom scales or functionating scales were analyzed (Tables V and VI).

What may be the medical impact of case based reasoning in breast cancer treatment? Two recent medical concepts make it worthwhile to develop better tools for retrospective data analysis:1) personalized medicine, and 2) shared decision making (43). The first concept means that each treatment decision should be governed by more patient data than those contained in the TNM system and the biological prognosis factors. The second concept means that the patient should be part of the decision making approach, which makes it necessary to provide the patient with more information about her possible disease outcome. One patient with breast cancer may ask whether she should have a distinct additional treatment such as ML-I. The use of a database with a given number of similar cases, some with the additional treatment and most without, will help to answer this question. For the concept of shared decision making, we have to provide data enabling the patient (with assistance of her physician) to make better treatment decisions, not based on the belief of either the patient, the physician, or both in a situation where no high standard prospective studies are available covering the individual situation of a given patient. Our method of similar case analysis delivers data-driven decision support.

Before drawing any conclusions from our data, the shortcomings of our approach have to be underlined. Patients with reported ML-I treatment are very infrequent in our study. Data from publications estimate that the proportion of complementary treatment in breast cancer is as high as $48.7 \%$ to $53 \%$, with ML-I treatment being one of the most preferred options $(46 \%)(10,44,45,46)$. This means that up to $22 \%$ of all breast cancer patients choose a complementary ML-I treatment of their breast cancer. A further disadvantage of our study may be that our selection method for similar cases is not optimal. Three fundamental arguments should be considered in addition: (1) our CBR procedure match the control cases with replacement, (2) control cases and cases with additional ML-I treatment cases were compared by ttest or chi square test, a method being criticized by Imai and coworkers (47), and (3) the interactions of the covariables are not taken into consideration. For all three restrictions of the CBR model improvement are currently under work.

For the hypothesis tested, analysis of our data using the similar case method did not hint towards a survival or life quality benefit or harm in the ML-I patients and their nonML-1 treated counterparts. However, the ongoing discussion about the benefits of additional ML-I treatment against the background of the undisputed biological effects of this substance (48-50, for review 50) can probably not be resolved by classical study approaches as shown by many different approaches in the past (51-52). Therefore, our approach can be considered as a data-driven hint, when a patient asks for a complementary ML-I treatment.

From our data analysis a patient or physician cannot conclude, that an additional ML treatment of breast cancer provides harm or benefit in disease outcome (RS or OVS) or life quality. Our analysis is in accordance with a recent 
patient cohort study of Tröger and coworkers (53) where ML-I treatment did not influence RFS.

\section{Acknowledgements}

This research was supported by the Robert Bosch Foundation, the Sabine-Dörges-Stiftung für krebskranke Kinder, Jugendliche und junge Erwachsene. The Authors thank the radiotherapists: Prof. Dr. Schmidt (Katharinen-Hospital Stuttgart, Germany), Prof. Dr. Metzger, and Prof. Dr. Hehr (Marienhospital, Stuttgart, Germany), the surgeons: PD Dr. Hoffmann (Marienhospital), Prof. Dr. Karg (Klinikum Stuttgart), and the doctors, Kuhn and Beldermann (KarlOlga-Hospital, Stuttgart, Germany) for providing the data.

\section{References}

1 Adjuvant-online, www.adjuvantonline.com (2014).

2 Horneber M, Bueschel G, Dennert G, Less D, Ritter E and Zwahlen M: How many patients use complementary and alternative medicine: a systematic review and metaanalysis. Integr Cancer Ther 11: 187-203, 2012.

3 Horneber MA, Bueschel G, Huber R, Linde K and Rostock M: Mistletoe therapy in oncology. Cochrane Database Syst Rev 2: CD003297, 2008.

4 Gutsch J: Außergewöhnlicher Krankheitsverlauf bei metastasierendem Mammakarzinom unter Misteltherapie nach pseudoallergischer Reaktion. In: Die Mistel in der Tumortherapie. Grundlagenforschung und Klinik. Scheer R, Bauer R, Becker H, Berg PA and Fintelmann V (eds.). KVC Verlag, Essen, pp. 379-387, 2001.

5 Schumacher K, Schneider B, Reich G, Stiefel T, Stoll G, Bock $\mathrm{PR}$, Hanisch $\mathrm{J}$ and Beuth $\mathrm{J}$ : Influence of postoperative complementary treatment with lectin-standardized mistletoe extract on breast cancer patients. A controlled epidemiological multicentric retrospective cohort study. Anticancer Res 23: 50815087, 2003.

6 Kienle GS, Berrino F, Büssing A, Portalupi E, Rosenzweig S and Kiene H: Mistletoe in cancer - a systematic review on controlled clinical trials. Eur J Med Res 8: 109-119, 2003.

7 Piao BK, Wang YX, Xie GR, Mansmann H, Beuth J and Lin HS: Impact of complementary mistletoe extract treatment on quality of life in breast, ovarian and non-small lung cancer cancer patients. A prospective randomized controlled clinical trial. Anticancer Res 24: 303-309, 2004.

8 Semiglasov VF, Stepula VV, Dudov A, Lehrmacher W and Mengs U: The standardised mistletoe extract PS76A2 improves QoL in patients with breast cancer receiving adjuvant CMF chemotherapy: a randomised placebo-controlled, double-blind, multicentric clinical trial. Anticancer Res 24: 1293-1302, 2004.

9 Lange-Lindberg AM, Velasco Garrido M and Busse R: Mistletoe treatments for minimising side effects of anticancer chemotherapy. GMS Health Technol Assess 2: Doc 18, 2006.

10 Fasching PA, Thiel F, Nicolaisen-Murmann K, Rauh C, Engel J Lux MP, Beckmann MW and Bani MR: Association of complementary methods with quality of life and life satisfaction in patients with gynecologic and breast malignancies. Support Care Cancer 15: 1277-1284, 2007.

11 Kienle GS and Kiene H: Complementary cancer therapy: a systematic review of prospective clinical trials on anthroposophic mistletoe extracts. Eur J Med Res 12: 103-119, 2007.
12 Beuth J, Schneider B and Schierholz JM: Impact of complementary treatment with the standardized mistletoe extract during aftercare: a controlled multicenter comparative epidemiological cohort study. Anticancer Res 28: 523-527, 2008.

13 Kienle GS, Glockmann A, Schink A and Kiene H: Viscum album L. extracts in breast and gynaecological cances: a systematic review of clinical and preclinical research. J Exp Clin Cancer Res 28: 79, 2009.

14 Kienle GS and Kiene H: Influence of Viscum album L (European mistletoe) extracts on quality of life in cancer patients: a systematic review of controlled clinical studies. Integr Cancer Ther 9: 142-157, 2010.

15 Eisenbraun J, Scheer R, Kröz M, Schad F and Huber R: Quality of life in breast cancer patients during chemotherapy and concurrent therapy with a mistletoe extract. Phytomedicine 18 : 151-157, 2011.

16 Tröger W, Zdrale Z, Tisma $\mathrm{N}$ and Matijasevic M: additional therapy with a mistletoe product during adjuvant chemotherapy of breast cancer patients improves quality of life: an open randomized clinical pilot trial. Evid Based Complement Alternat Med 2014: 430518, 2014.

17 Grossarth-Maticek R and Ziegler R: Randomized and nonrandomized prospective controlled cohort studies in matched pair design for the long-term therapy of breast cancer patients with a mistletoe preparation (Iscador): a re-analysis. Eur J Med Res 11: 485-495, 2006.

18 Grossarth-Maticek R and Ziegler R: Prospective controlled cohort studies on long-term therapy of breast cancer patients with a mistletoe preparation (Iscador). Forsch Komplementmed 13: 285-292, 2006

19 Dippon J, Fritz P and Kohler M: A statistical approach to case based reasoning with application to breast cancer data. Comput Stat Data Anal 40: 570-602, 2002.

20 Klenk S, Dippon J, Fritz P and Heidemann G: Interactive survival analysis with the OCDM system: From development to application. Inf Syst Front 11: 391-403, 2009.

21 Wittekind C and Meyer JM: TNM. Klassifikation maligener Tumoren. 6. Und 7. Auflage, Wiley -Blackwell, Auflage, 2010.

22 Remmele W and Stegner HE: Recommendation for uniform definition of an immunoreactive score (IRS) for immunohistochemical estrogen receptor detection (ER-ICA) in breast cancer tissue. Pathologe 8: 138-140, 1987.

23 Austin PC: The use of propensity score methods with survival or time-to-event outcomes: reporting measures of effect similar to those used in randomized experiments. Stat Med 33: 12421258, 2014.

24 Schöffski P, Riggert S, Fumoleau P, Campone M, Bolte O, Marreaud S, Lacombe D, Baron B, Herold M, Zwierzina H, Wilhelm-Ogubiyi K, Lentzen $\mathrm{H}$ and Twelves C, European Organization for Research and treatment of Cancer New Drug Development Group: Phase I trial of intravenous aviscumine (rViscumin) in patients with solid tumors: a study of the European Organization for Research and Treatment of Cancer New Drug Development Group. Ann Oncol 15: 1816-1824, 2004.

25 Trautmann C: Retrospektive Datenanalyse anhand von Therapiedaten zum Mammakarzinom des onkologischen Schwerpunkts Stuttgart. Medical thesis. University of Tuebingen, 2012. 
26 Statistisches Bundesamt Deutschland. https://www.destatis.de

27 EORTC-QLQ-C30 http://groups.eortc.be/qol/sites/default/files /img/slider/specimen_qlq-c30_english.pdf 2015.

28 Ilin E: Neurotoxizität und Langzeitauswirkung auf die Lebensqualität durch adjuvante Taxantherapie bei Mammakarzinom. Medical thesis. University of Tuebingen, 2012.

29 R Core Team: R: A language and environment for statistical computing. R Foundation for Statistical Computing, URL http:www.R-project.org 2014.

$30 \mathrm{http}: / /$ sipemu.github.io/case-based.reasoning/index.html

31 Collett D: Modelling Survival Data in Medical Research. 2nd ed., Chapman \&Hall, 2003.

32 Austin PC: Balance diagnostic for comparing the distribution of baseline covariates between treatment groups in propensity-score matched samples. Stat Med 28: 3083-3107, 2009.

33 Beuth J, Ko HL, Gabius HJ, Burrichter H, Oette K and Pulverer $\mathrm{G}$ : Behavior of lymphocyte subsets and expression of activation markers in response to immunotherapy with galactoside-specific lectin from mistletoe in breast cancer patients. Clin Invest 70: 658-661, 1992.

34 Beuth J, Stoffel B, Ko HL, Buss G, Tunngal L and Pulverer G: Immunoactive effects of various lectin-1 dosages in mammary carcinoma patients. Arzneimittelforschung 45: 505-507, 1995.

35 Büssing A, Stumpf C, Tröger W and Schietzel M: Course of mitogen-stimulated $\mathrm{T}$ lymphocytes in cancer patients treated with Viscum album extracts. Anticancer Res 27: 2903-2910, 2007.

36 Heiny BM, Albrecht V and Beuth J: Correlation of immune cell activities and beta- endorphin release in breast carcinoma patients treated with galactose-specific lectin standardized mistletoe extract. Anticancer Res 18: 583-586, 1998.

37 Stein G, Henn W, von Laue H and Berg P: Modulation of the cellular and humoral immune responses of tumor patients by mistletoe therapy. Eur J Med Res 3: 194-202, 1998.

38 Pae HO, Seo WG, Oh GS, Shin MK, Lee HS, Lee HS, Kim SB and Chung HT: Potentiation of tumor necrosis factor-alphainduced apoptosis by mistletoe lectin. Immunopharmacol Immunotoxicol 22: 697-709, 2000.

39 Franz H: Mistletoe lectins and their A and B chains. Oncol 43: 23-34, 1986.

40 Schumacher U, Stamouli A, Adam E, Peddie M and Pfüller U: Biochemical, histochemical and cell biological investigations on the actions of mistletoe lectins I, II, and III with human breast cancer cell lines. Glycoconj J 12: 250-257, 1995.

41 Fritz P, Dippon J, Kierschke T, Siegle I, Möhring A, Moisa A and Mürdter TE: Impact of mistletoe lectin in breast cancer. Anticancer Res 24: 1187-1192, 2004.
42 Aulitzky W and Becker G: Aufbau klinischer Krebsregister. Der Onkologe 17: 115-120, 2011.

43 Windeler J, Lauterberg J, Wieseler B, Sauerland S and Lange S: Patientenregister für die Nutzenbewertung. Kein Ersatz für randomisierte Studien. Deutsches Ärzteblatt 114: A783-6, 2017.

44 Barry MJ and Edgman-Levitan S: Shared decision making-The pinnacle of patient-centered care. N Engl J Med 306: 780-781, 2012.

45 Nilsson J, Kallman M, Östlund U, Holgersson G, Bergqvist M and Bergström S: The use of complementary and alternative medicine in Scandinavia. Anticancer Res 36: 3243-3251, 2016.

46 Schönekaes K, Micke O, Mücke R, Büntzel J, Glatzel M, Bruns $\mathrm{F}$ and Kisters $\mathrm{K}$ : Use of complementary/alternative therapy methods by patients with breast cancer. Forsch Komplementarmed Klass Naturheilk 10: 304-308, 2003.

47 Imai K, King G and Stuart EA: Misunderstandings between experimentalists and observationalist about casual interference. Z R Statist Soc A 171: 481-502, 2008.

48 Hajto T, Hostanska K and Gabius HJ: Modulatory potency of the beta-galactoside-specific lectin from mistletoe extract (Iscador) on the host defense system in vivo in rabbits and patients. Cancer Res 49: 4803-4808, 1989.

49 Kröz M, Schad F, Matthes B, Pickartz H and Girke M: Blood and tissue eosinophilia, mistletoe lectin antibodies and quality of life in a breast cancer patient undergoing intratumoral and subcutaneous mistletoe lectin therapy. Forsch Komplementarmed Klass Naturheilkd 9: 160-167, 2002.

50 Scheer R, Bauer R, Becker H, Berg PA and Fintelmann V: Die Mistel in der Tumortherapie. Grundlagenforschung und Klinik KVC, Essen, 2001.

51 Gerhard I, Abel U, Loewe-Mesch A, Huppmann S and Kuehn $\mathrm{JJ}$ : Problems of randomized studies in complementary medicine demonstrated in a study on mistletoe treatment of patients with breast cancer. Forsch Komplementarmed Klass Naturheilkd 11: 150-157, 2004.

52 Kienle SG and Kienle H: Die Mistel in der Onkologie. Fakten und konzeptionelle Grundlagen. Detaillierte Darstellung der einzelnen Studien. Schattauer Verlag, pp. 552-556, 2003.

53 Tröger W, Zdrale Z and Stankovic N: 5-Jahres-Nachbeobachtung von Patientinnen mit Brustkrebs nach einer randomisierten Studie mit Viscum-album (L) Extrakt. Deutsche Zeitschrift für Onkologie 48: 105-110, 2016.

Received December 11, 2017

Revised January 16, 2018

Accepted January 17, 2018 